\title{
Determination of Mercury in Wastewater Using a Molecularly Imprinted Polymer as Solid Phase Extraction Sorbent and CV-ICP-OES
}

\author{
Roi Rodríguez-Fernández, Elena Peña-Vázquez, and Pilar Bermejo-Barrera* \\ Department of Analytical Chemistry, Nutrition and Bromatology, Faculty of Chemistry, \\ Universidade de Santiago de Compostela \\ Avenida das Ciencias s/n, E-15782, Santiago de Compostela, Spain
}

\section{INTRODUCTION}

More than 140 nations signed a binding treaty in 2013 to reduce the release of mercury which has accumulated in the environment as a result of industrial and mining activities (1). One of the most promising sorbents for wastewater treatment and monitoring of metals are the ionic imprinted polymers due to their selectivity, because they are made with specific cavities for target analytes $(2,3)$. The polymers for remediation of waters are synthesized using $\mathrm{Hg}$ (II) as a template and ligands containing sulfur or nitrogen donating atoms such as dithizone (4), vinylcarbazole (5), or aminothiophenol (6). Mercury(II) imprinted materials such as crop stalks (7), polyaminated chitosan derivatives (8), cellulosic cotton fibers (9), or chelating fibers based on poly(ethylene terephthalate) (10) have also been used for the removal of mercury from waters. Solid phase extraction (SPE) has been performed previous to the analysis of waters using diazoaminobenzene-vinylpyridine copolymers (11), and imprinted polymeric sorbents with 1-(2-thiazolylazo)-2naphthol (12), 4-(2-thiazolyazo) resorcinol (13), aminothiol monomers $(14,15)$, tetrakis $(3-$ hydroxyphenyl)porphyrin $(16,17)$, 2-vinylpyridine (18), 2,2'-di pyridyl amine (19), 8-hydroxyquinoline (20), and 1-(2-acetatophenyl)-3-(4methylphenyl) triazine (21). Yordanova et al. (22) also synthesized polymeric ion-imprinted nanoparticles for mercury speciation in sur-

\footnotetext{
*Corresponding author.

E-mail: pilar.bermejo@usc.es

Tel: + 34881814266

Fax: + 34981547141
}

\begin{abstract}
In this study, a molecularly imprinted polymer based on the formation of the phenobarbitalmethylmercury complex was used as a solid phase extraction sorbent for the preconcentration of mercury in waters and subsequent analysis by CV-ICP-OES. A number of important operating parameters were optimized: $\mathrm{pH}$ of the sample $(\mathrm{pH}=8)$, sample flow rate, elution volume $(5 \mathrm{~mL}$ of $1 \mathrm{M}$ thiourea/ $1 \mathrm{M} \mathrm{HCl}$ ), mass of polymer in the cartridge $(300 \mathrm{mg})$, and volume of sample $(200 \mathrm{~mL})$. The analytical performance of the method was evaluated with good recovery $(105 \%)$ at $0.05 \mu \mathrm{g} \mathrm{L}^{-1}$ of mercury (environmental quality standard established by the European Union) and a preconcentration factor of 40 . The method was also applied to the analysis of wastewater samples.
\end{abstract}

face waters with 1-pyrrolidinedithiocarboxylic acid as complexing agent.

Several authors have developed organic-inorganic hybrid materials using thiol-functionalized mesoporous sorbents and methanesulfonic acid $(23,24)$, an imprinted amino-functionalized silica gel sorbent (25), 3-isocyanatopropyltriethoxysilane bearing thymine bases (26), a double imprinting technique with cetyltrimethylammonium bromide (CTAB) as a second template to improve the efficiency of the polymer $(27,28)$, or maghemite nanoparticles with mercaptoethylamino as functional monomer (29). A dithizone- $\mathrm{Hg}^{2+}$ imprinted sorbent was synthesized by a sol-gel process and applied to speciation (30). Electrochemical (31-38) and optical sensors $(39,40)$ for $\mathrm{Hg}$ (II) based on imprinted polymers as recognition elements have also recently been developed.

Few studies have used methylmercury as a template to synthesize the imprinted polymers with methylmercury-methacryloyl-(L)cysteine (41), 4-(ethenylphenyl)-4formate-6-phenyl-2,2'-bipyridine (42) or 3-methyl-5-(methylthio)-4vinylthiophene-2-carboxylic acid (VTCA) (43) as monomers. Mercury has been used in classical methods for the analysis of barbiturates in biological fluids (44-46). In a previous work (47), the present authors synthesized a methylmercuryimprinted polymer using phenobarbital as a ligand which was applied to the determination of methylmercury in two certified reference materials of marine products after an extraction step with toluene. The polymer is versatile and can also be applied to the speciation of organic forms of mercury by HPLCICP-MS (48). In this study, use of a polymer for the preconcentration of waters and analysis by CV-ICPOES was evaluated and applied to the analysis of several waste-water samples.

\section{EXPERIMENTAL}

\section{Instrumentation}

Mercury was analyzed using an Optima $^{\text {TM }} 3300 \mathrm{DV}$ inductively coupled plasma optical emission spectrometer (ICP-OES) (PerkinElmer, Inc., Shelton, CT, USA). The Optima spectrometer system includes a three-channel, softwarecontrolled peristaltic pump for mixing the sample solutions and the 
sodium borohydride reducing solution. A homemade gas-liquid separator with forced outlet was connected to the torch using a 60-cm PTFE tube, and the liquid was pumped to waste using a Minipuls $^{\text {TM }} 3$ peristaltic pump (Gilson, Villiers-le-Bel, France). All connections in the vapor generation system were made of PTFE tubing of $0.5 \mathrm{~mm}$ i.d., including the 500- $\mu \mathrm{L}$ reaction loop.

The concentrations determined after the analysis of the wastewater samples were also compared to the results obtained using a PerkinElmer ${ }^{\circledR}$ flow injection mercury system (FIMS).

The polymer was synthesized using a Movi-Rod roll and tilt mixer (Selecta, Barcelona, Spain) placed into the Boxcult temperature-controlled incubation chamber (Selecta). A pH meter model 720 (Thermo Orion, Waltham, MA, USA) was used to adjust the $\mathrm{pH}$ of the samples proir to the SPE procedure. The Minipuls ${ }^{\mathrm{TM}} 3$ peristaltic pump (Gilson, Villiers, France) was also used in the SPE experiments in column mode.

The following instruments were used for the characterization of the synthesized polymer (47): FLASH 1112 elemental analyzer (Thermo Finnigan (Waltham, MA, USA), EVO LS 15 microscope (Zeiss, Oberkochen, Germany) to obtain the micrographs, and a labmade spectrometer (Servicios Generales USC (General Services, University of Santiago de Compostela, Spain) with an anode of Mo for energy dispersive $\mathrm{x}$-ray dispersion fluorescence measurements.

\section{Reagents}

All solutions were prepared using ultra-pure water of $18 \mathrm{M} \Omega \cdot \mathrm{cm}$ resistance obtained from a Milli-Q ${ }^{\circledR}$ purification system (Millipore Corporation, USA).
Methylmercury chloride, methacrylic acid (MMA), ethylene dimethacrylate (EDMA), and phenobarbital and thiourea (Sigma, Steinhelm, Germany). The stock standard solution (1000 $\mathrm{mg} \mathrm{L}^{-1}$ ) of $\mathrm{Hg}$ (II) was from Merck (Darmstadt, Germany). For polymerization, 2,2' azobisisobutyronitrile (AIBN) was used (purchased from Fluka, Steinhelm, Germany). All other chemicals (ammonia for the preparation of the buffer, hydrochloric acid, acetonitrile, toluene) were purchased from Panreac and Scharlau (Barcelona, Spain).

All glass and plastic material was cleaned and kept in 10\% (w/w) nitric acid for at least 48 hours. The material was then rinsed three times with ultra-pure water before use.

\section{Synthesis of the Molecularly Imprinted Polymer}

The molecularly imprinted polymer (MIP) was synthesized using a precipitation method previously reported (47). Briefly, the procedure consists of the following steps: - Preparation of the pre-polymerization mixture (for approximately $1.5 \mathrm{~g}$ of polymer, an amount of $0.075 \mathrm{mmol}$ of $\mathrm{MeHgCl}, 0.3 \mathrm{mmol}$ of phenobarbital, $0.75 \mathrm{mmol}$ of MAA, and $12 \mathrm{~mL}$ of the porogen acetonitrile:water [4:1] was mixed and kept in darkness overnight); - polymerization at $60^{\circ} \mathrm{C}$ for 24 hours after addition of $4.5 \mathrm{mmol}$ of the cross-linker EDMA and 0.25 mmol of AIBN (initiator); - after removal of the template, portions of the dry polymer (150 $\mathrm{mg}$ ) were packed in 5-mL syringes between Teflon ${ }^{\circledR}$ frits and treated with $200 \mathrm{~mL}$ of $1 \mathrm{M}$ thiourea in $1 \mathrm{M}$ $\mathrm{HCl}$ at a flow rate of $1 \mathrm{~mL} \cdot \mathrm{min}^{-1}$.

\section{Solid Phase Extraction Procedure}

Portions of the MIP (300 mg) were packed in 5-mL syringes used as SPE cartridges. The cartridges were conditioned with $0.1 / 0.1 \mathrm{M}$ $\mathrm{NH}_{3} / \mathrm{NH}_{4}{ }^{+}$buffer solution at $\mathrm{pH} 8.0$ and the $\mathrm{Hg}$ (II) buffered standards or samples (typically $200 \mathrm{~mL}$ ) were loaded at a flow rate of 0.5 $\mathrm{mL} \min ^{-1}$. The cartridges were washed with the buffer solution, and elution was performed using $5 \mathrm{~mL}$ of $1 \mathrm{M}$ thiourea in $1 \mathrm{M} \mathrm{HCl}$ at the same flow rate. The cartridges were kept in buffer solution after thiourea. Afterwards, the acidic thiourea extracts were analyzed by CV-ICP-OES.

\section{Determination of Mercury by CV-ICP-OES}

The determination of mercury was performed by ICP-OES after generation of the elemental cold vapor using a continuous-flow system. The samples were mixed with the reducing solution of $0.2 \%(\mathrm{w} / \mathrm{v})$ $\mathrm{NaBH}_{4}$ stabilized with $0.05 \%$ (w/v) $\mathrm{NaOH}$. The reagents were transferred to the gas-liquid separator through a 500- $\mu \mathrm{L}$ reaction loop and an 8-way peristaltic pump (Gilson, Villiers, France) equipped with a $3.18 \mathrm{~mm}$ i.d. Tygon tube used for extracting the waste from the gasliquid separator. The $\mathrm{Hg}$ vapor was separated from the liquid mixture and swept to the torch using a 0.8 $\mathrm{L}$ min $^{-1}$ Ar flow rate. The operating conditions used for cold vapor generation and detection of mercury by ICP-OES are summarized in Figure 1 and Table I, respectively.

\section{RESULTS AND DISCUSIONS}

\section{Optimization of Working Conditions}

The use of the MIP in column mode avoids losing mass of the polymer as well as time-consuming steps in solid phase extraction, such us weighing the polymer or filtering after extraction. In this study, the MIP was used in column mode as reported in previous studies $(11,18,23)$, and some of the operating parameters were optimized such as $\mathrm{pH}$ of the sample, sample loading flow rate, elution volume and mass of polymer. 


\section{Influence of $\mathrm{pH}$ on MIP Retention}

Standards of $50 \mu \mathrm{g} \mathrm{L}^{-1}$ of $\mathrm{Hg}^{2+}$ (25 mL) buffered at $\mathrm{pH}$ 6.0, 7.0, 8.0, and 9.0 were loaded in duplicate at $0.5 \mathrm{~mL} \mathrm{~min}^{-1}$ into cartridges containing 150-mg portions of the polymer. Afterwards, mercury was eluted with $10 \mathrm{~mL}$ of $1 \mathrm{M}$ thiourea/ $1 \mathrm{M} \mathrm{HCl}$. Similar experiments were performed using $50 \mu \mathrm{g} \mathrm{L}^{-1}$ of $\mathrm{MeHg}^{+}$. It was observed that the $\mathrm{pH}$ affects the recovery of $\mathrm{MeHg}^{+}$, whereas the recovery of $\mathrm{Hg}$ (II) is almost constant in the interval of the $\mathrm{pH}$ studied with a small decrease at $\mathrm{pH} 7.0$ (Figure 2). As a compromise solution, $\mathrm{pH} 8.0$ was selected to perform all further experiments.
The $\mathrm{pH}$ used for sample loading depends on the type of ligand selected to complex mercury. The $\mathrm{pH}$ in the present study is higher than was used with other methylmercury imprinted polymers with (4-ethenylphenyl)-4-formate6-phenyl-2,2'-bipyridine ( $\mathrm{pH} 5.0$ ) (11), or methacryloyl-(L)-cysteine methylester ( $\mathrm{pH} 7.0)$ as ligands (41), or $\mathrm{Hg}$ (II) imprinted polymer (pH 6) with vinylcarbazole (5). However, in the case of the polymer with 2,2'-di pyridyl amine, the $\mathrm{pH}$ used to load the sample was 9.5 (19).

\section{Selection of Elution Volume}

An experiment was performed to reduce the elution volume and

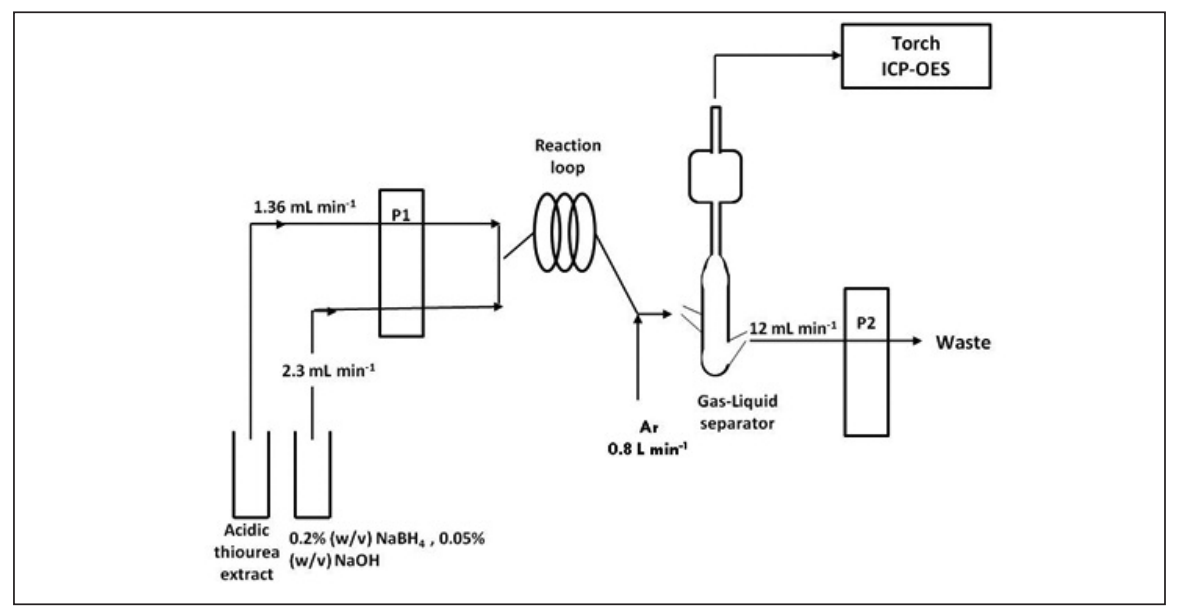

Fig. 1. Operating conditions of the cold vapor generation system.

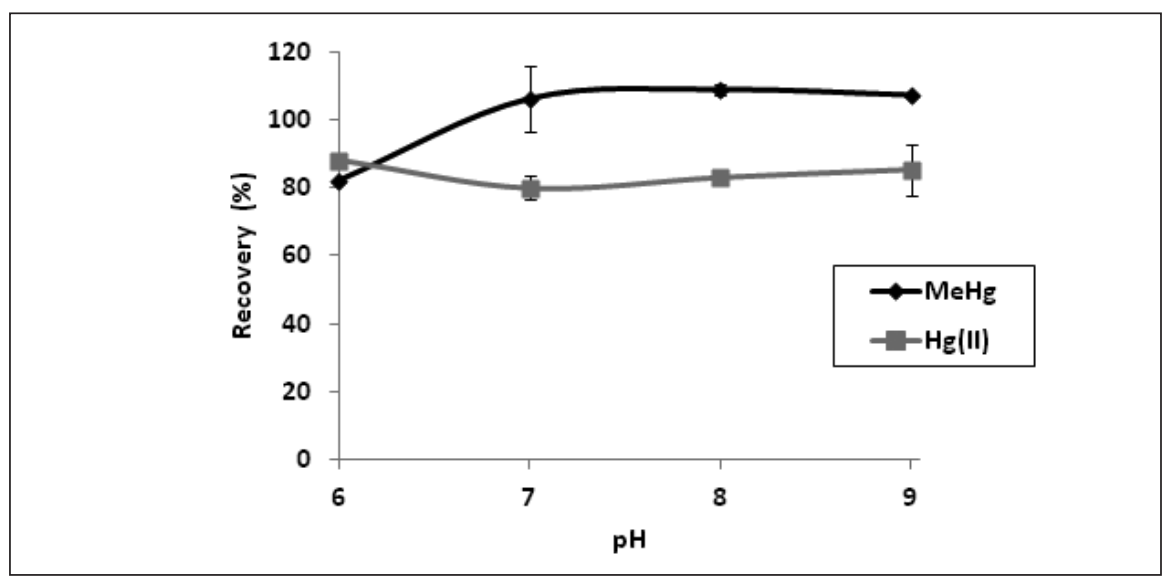

Fig. 2. Influence of $\mathrm{pH}$ on the retention of $\mathrm{Hg}(\mathrm{II})$ and $\mathrm{MeHg}^{+}$.

increase the sensitivity in the determinations by CV-ICP-OES. A standard of $0.9 \mu \mathrm{g} \mathrm{L}^{-1} \mathrm{Hg}(\mathrm{II})(25 \mathrm{~mL})$ buffered at $\mathrm{pH} 8.0$ was loaded at a flow of $0.5 \mathrm{~mL} \mathrm{~min} \mathrm{~m}^{-1}$ into a $150-\mathrm{mg}$ cartridge. Mercury was eluted from the polymer using portions of 2.5 $\mathrm{mL}$ of $1 \mathrm{M}$ thiourea/1 M HCl. Only $50 \%$ of the analyzed mercury was eluted in the first portion and another $2.5 \mathrm{~mL}$ portion was needed to elute the remaining mercury. Therefore, a volume of $5 \mathrm{~mL}$ of acidic thiourea was used in further experiments to elute the element from the cartridge.

\section{Influence of Sample Loading Flow Rate}

The loading flow rate was studied at four different values $(0.5$, 1.0, 2.5, and $\left.5.0 \mathrm{~mL} \mathrm{~min}^{-1}\right)$ using $0.9 \mu \mathrm{g} \mathrm{L}^{-1} \mathrm{Hg}$ (II) standards (25 mL) buffered at $\mathrm{pH}$ 8.0. The results indicated that a low flow rate must be used to increase recovery (Figure 3 ); therefore, a flow of $0.5 \mathrm{~mL} \mathrm{~min}^{-1}$ was selected for further extractions. An elution flow rate of $0.5 \mathrm{~mL} \mathrm{~min}^{-1}$, previously selected (47), was used for all further experiments.

TABLE I

Instrumental Operating Conditions for CV-ICP-OES Determination of $\mathbf{H g}$

\begin{tabular}{lr}
\hline Hg Wavelength & $253.652 \mathrm{~nm}$ \\
ICP RF Power & $1300 \mathrm{~W}$ \\
Argon Flow: & \\
$\quad$ Plasma & $15 \mathrm{~L} \mathrm{~min}^{-1}$ \\
Nebulizer & $0.8 \mathrm{~L} \mathrm{~min}^{-1}$ \\
Auxiliary & $0.5 \mathrm{~L} \mathrm{~min}^{-1}$ \\
Viewing Height & $15 \mathrm{~mm}^{-}$ \\
Measurement Mode & Axial \\
Purge Gas Flow & Normal \\
Aperture Size & Normal \\
Read Delay & $40 \mathrm{~s}$ \\
Replicates & 5 \\
Integration Time & Auto \\
\hline
\end{tabular}




\section{Selection of the Mass of Polymer Used for SPE}

$\mathrm{Hg}$ (II) aqueous standards were loaded at different concentrations (ranging from $50 \mathrm{ng} \mathrm{L}^{-1}$ to $25 \mu \mathrm{g} \mathrm{L}^{-1}$ ) and sample volumes of $10 \mathrm{~mL}$ to $200 \mathrm{~mL}$ using syringes containing 150 or $300 \mathrm{mg}$ packaged MIP. The average recovery increased successfully to $100 \pm 15 \%$ using $300 \mathrm{mg}$ of polymer due to the larger breakthrough volume and $\mathrm{Hg}$ retention capacity. Therefore, $300 \mathrm{mg}$ of polymer was introduced into the cartridges prior to the analysis of the wastewater samples. The mass of mercury expected in the water samples is lower than the capacity of the MIP sorbent which decreases starting from $20 \mu \mathrm{g} \mathrm{g}^{-1}$ polymer onwards.

\section{ANALYTICAL PERFORMANCE}

\section{Calibration Graphs}

The standards were prepared with concentrations of $0,2.5,5.0$, 7.5, and $10.0 \mu \mathrm{g} \mathrm{L}^{-1}$ of $\mathrm{Hg}$ (II) in $1.0 \mathrm{M}$ thiourea/1 $\mathrm{M} \mathrm{HCl}$ and analyzed by CV-ICP-OES using the conditions shown in Table I and Figure 1. The equation of the obtained calibration graph was: A = 98.291 [Hg]1.092 , with a regression coefficient value of 0.999 (Figure 4).

\section{Limit of Detection and Quantification}

The limit of detection (LOD) is defined as the element concentration corresponding to three times the standard deviation of the measurement of a blank $(n=11)$. The limit of quantification (LOQ) is calculated as 10 times the standard deviation of the measurement of a blank. An instrumental LOD of 0.8 $\mu \mathrm{g} \mathrm{L}^{-1}$ was obtained when a solution of $1 \mathrm{M}$ thiourea/ $1 \mathrm{M} \mathrm{HCl}$ was used as the blank. The instrumental LOQ was $2.7 \mu \mathrm{g} \mathrm{L}^{-1}$. The LOD and LOQ of the sample was 0.02 and 0.07 $\mu \mathrm{g} \mathrm{L} \mathrm{L}^{-1}$, respectively, for a preconcentration factor of 40 and $200 \mathrm{~mL}$ of sample. The LOQ value of the present study was found to be lower than the environmental quality standards established by the European Union for mercury and its compounds in surface waters of $0.05 \mu \mathrm{g} \mathrm{L}^{-1}$ (annual average) and $0.07 \mu \mathrm{g} \mathrm{L}^{-1}$ (maximum allowable concentration) (49).

\section{Accuracy}

To evaluate accuracy, the recovery was studied after applying the solid phase extraction procedure and analysis by CV-ICP-OES to different samples containing mercury at different concentration levels (Table II). First, buffered standards of $0.36 \mu \mathrm{g} \mathrm{L}^{-1} \mathrm{Hg}$ (II) $(25 \mathrm{~mL})$ were

\section{Atomic Apectroscopy \\ 1 Vol. 37(6), Nov./Dec. 2016}

loaded into 300-mg MIP cartridges in duplicate, and the recovery obtained was $100 \pm 16 \%$, with a preconcentration factor of 5 . The preconcentration procedure was applied to a standard containing $0.05 \mu \mathrm{g} \mathrm{L}^{-1}$ of mercury (environmental quality standards established by the European Union, annual average). A volume of $200 \mathrm{~mL}$ of sample was loaded into the cartridge in duplicate and eluted with $5 \mathrm{~mL}$ of $1 \mathrm{M}$ thiourea/1M HCl (preconcentration factor: 40). The eluate was analyzed by CV-ICP-OES and the calculated concentration in the sample was $0.0525 \mu \mathrm{g} \mathrm{L}^{-1}$, corresponding to a recovery of $105 \pm 24 \%$. The analytical recovery was also calculated after the addition of $0.3 \mu \mathrm{g} \mathrm{L}^{-1} \mathrm{Hg}$ (II) to a diluted wastewater sample. The average value

TABLE II

Accuracy in the Determination of $\mathrm{Hg}$

\begin{tabular}{|c|c|c|}
\hline $\begin{array}{l}\text { Conc. } \\
\left(\mu \mathrm{g} \mathrm{L}^{-1}\right)\end{array}$ & $\begin{array}{l}\text { Experi- } \\
\text { mental } \\
\text { Conc. } \\
\left(\mu \mathrm{g} \mathrm{L}^{-1}\right)\end{array}$ & $\begin{array}{c}\text { Recovery } \\
\text { (\%) }\end{array}$ \\
\hline 0.05 & $0.0525 \pm 0.012$ & $105 \pm 24$ \\
\hline 0.36 & $0.36 \pm 0.06$ & $100 \pm 16$ \\
\hline
\end{tabular}

0.30 (addition

to diluted

wastewater) $\quad 0.31 \pm 0.02 \quad 104 \pm 2$

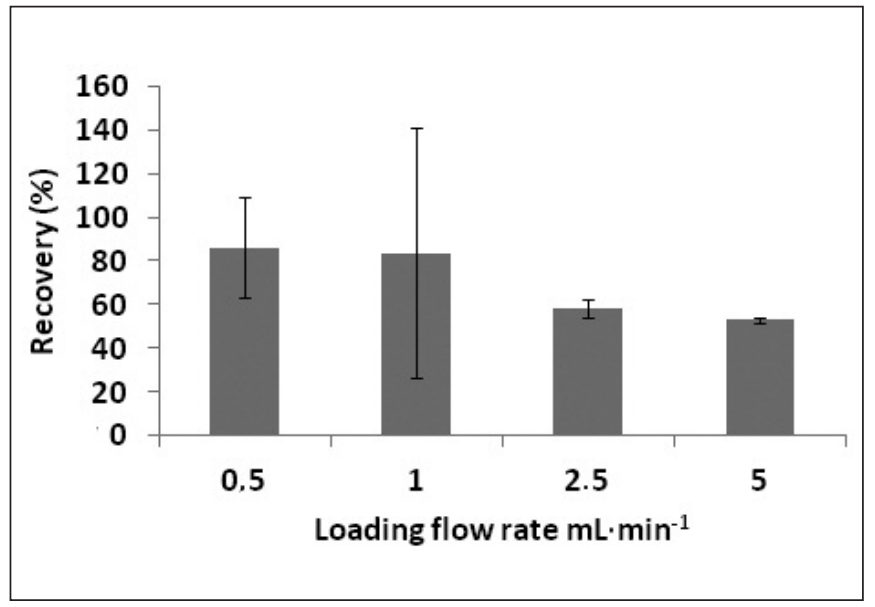

Fig. 3. Influence of Sample Loading Flow Rate.

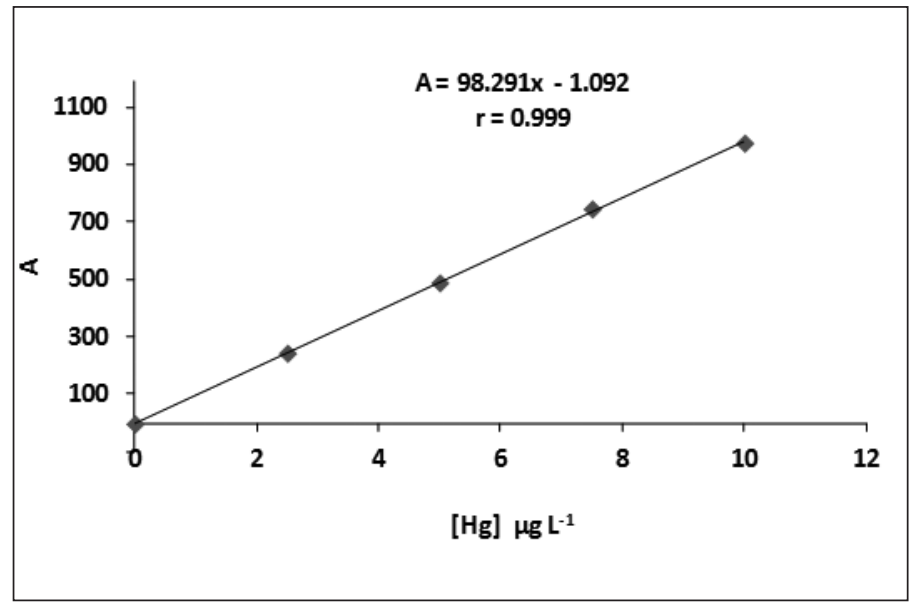

Fig. 4. Calibration graph obtained for the determination of $\mathrm{Hg}$. 
obtained with the standard deviation was $104 \pm 2 \%$ (Table II).

\section{Reproducibility}

The reproducibility of the whole procedure (solid phase extraction and determination of mercury by CV-ICP-OES) was evaluated after applying the procedure to five replicates of a diluted wastewater (1:100). The following concentrations were obtained for the replicates: $4.97,3.74,4.71,4.87$, and $4.63 \mu \mathrm{g} \mathrm{L}^{-1}$. The mean concentration \pm standard deviation measured in the sample was $4.58 \pm 0.49 \mu \mathrm{g} \mathrm{L}^{-1}$, with a standard relative deviation of $10.7 \%$. The cartridges containing $300 \mathrm{mg}$ of the imprinted polymer were reused more than 20 times before being discarded.

\section{Applications}

The method was applied to the analysis of 5 wastewater samples that had been previously analyzed using a flow injection mercury system (FIMS), a PerkinElmer CV-AAS instrument. The samples were acidified to $\mathrm{pH}<1$ and kept at $4{ }^{\circ} \mathrm{C}$ before analysis.

The analyzed samples were diluted (1:100), undiluted concentrations ranging from 5 to 49 $\mu \mathrm{g} \mathrm{L}^{-1}$. The samples were diluted 1:100, $200 \mathrm{~mL}$ were loaded in duplicate into the SPE cartridges, and the acidic thiourea extracts were analyzed by CV-ICP-OES. The concentration values provided by the supplier, the concentration values calculated, and the recoveries are listed in Table III.

\section{CONCLUSION}

Solid phase extraction using an imprinted polymer is a good choice for the determination of mercury in waters. Preconcentration factors of 40 were obtained with the methylmercury imprinted polymer using phenobarbital as a ligand, thus allowing the determination of $\mathrm{Hg}$ by CV-ICP-OES in samples with con- centrations lower or similar to the environmental quality standards established by the European Union for mercury $\left(0.05-0.07 \mu \mathrm{g} \mathrm{L}^{-1}\right)$. The developed method was also applied successfully to the analysis of diluted wastewaters.

\section{ACKNOWLEDGMENT}

This study received the support of the Regional Government of Galicia, Spain (Consellería de Cultura, Educación e Ordenación Universitaria, GRC 2014/016). The authors wish to thank Sogarisa (Sociedad Gallega de Residuos Industriales) for providing the wastewater samples used in this project.

$\overline{\text { Received March 22, } 2016 .}$

\section{REFERENCES}

1. D.P. Krabbenhoft and E.M. Sunderland, Science 341, 1457 (2013).

2. D.L. Huang, R.Z. Wang, Y.G. Liu, G.M. Zeng, C. Lai, P.Xu, B.A. Lu, J.J. Xu, C. Wang and C. Huang, Environ. Sci. Pollut. Res. 22, 963 (2015).

3. P.E. Hande, A.B. Samui and P.S. Kulkarni, Environ. Sci. Pollut. Res. 22, 7375 (2015).

4. S. Ashraf, A. Cluley, C. Mercado and A. Mueller, Water Sci. \& Technol. 64, 1325 (2011).

5. L.H. Yze, N.A. Yusof, N.A.M. Maamor and N.H. Azeman, Asian J. Chem.
26, 16 (2014).

6. S.R. Thakare, M.R. Pal and S.Z. Jadhao, Des. Monomers Polym. 18, 650 (2015).

7. J. Wang, Faming Zhuanli Shenqing (2014) CN 103769059 A 20140507.

8. X. Tang, D. Niu, C. Bi and B. Shen, Ind. Eng. Chem. Res. 52, 13120 (2013).

9. M. Monier, I.M. Kenawy and M.A. Hashem, Carbohydr. Polym. 106, 49 (2014).

10. M. Monier and D.A. Abdel-Latif, Chem. Eng. J. 221, 452 (2013).

11. Y. Liu, X. Chang, D. Yang, Y. Guo and S. Meng, Anal. Chim. Acta 538, 85 (2005).

12. I. Dakova, I. Karadjova, V. Georgieva and G. Georgiev, Talanta 78, 523 (2009).

13. D.K. Singh and S. Mishra, Desalination 257, 177 (2010).

14. M. Firouzzare and Q. Wang, Talanta 101, 261 (2012).

15. M. Firouzzare, Adv. Mater. Res. 718720, 645 (2013).

16. M. Shamsipur, H.R. Rajabi, M.H. Beyzavi and $H$. Sharghi, Microchim. Acta 180, 791 (2013).

17. H.R. Rajabi, M. Shamsipur, M.M. Zahedi and M. Roushani, Chem. Eng. J. 259, 330 (2015).

18. M. Soleimani and M. G. Afshar, J. Anal. Chem. 70, 5 (2015).

19. M. Roushani, S. Abbasi and H. Khani, Environ. Monit. Assess. 187, 601 (2015).

20. F. Luo, S. Huang, X. Xiong and X.
TABLE III

Hg(II) Concentration in Analyzed Samples

\begin{tabular}{cccc}
\hline Sample & $\begin{array}{c}\text { Provided } \\
\text { Concentration } \\
\left(\mu \mathrm{g} \mathrm{L}^{-1}\right)\end{array}$ & $\begin{array}{c}\text { Calculated } \\
\text { Concentration } \\
\left(\mu \mathrm{g} \mathrm{L}^{-1}\right)\end{array}$ & $\begin{array}{c}\text { Recovery } \\
(\%)\end{array}$ \\
\hline 1 & $5.0 \pm 0.1$ & $5.6 \pm 0.3$ & $112 \pm 6$ \\
2 & $49.0 \pm 1.0$ & $53.5 \pm 0.1$ & $109 \pm 1$ \\
3 & $11.6 \pm 0.4$ & $12.1 \pm 0.7$ & $104 \pm 6$ \\
4 & $29.5 \pm 0.7$ & $23.7 \pm 6.8$ & $80 \pm 23$ \\
5 & $3.9 \pm 0.8$ & $3.4 \pm 0.2$ & $88 \pm 6$ \\
\hline
\end{tabular}




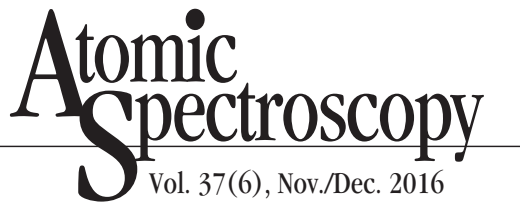

Lai, RSC Adv. 5, 67365 (2015).

21. B. Hashemi, M. Shamsipur, A. Javadi, M.K. Rofouei, A. Shockravi, N. Tajarrod and N. Mandumy, Anal. Meth. 7, 9641 (2015).

22. T. Yordanova, I. Dakova, K. Balashev and I. Karadjova, Microchem. J. 113, 42 (2014).

23. Z. Fan, Talanta 70, 1164 (2006).

24. Z. Wang, G. Wu and C. He, Microchim. Acta 165, 151(2009)

25. H. Zheng, T. Geng and L. Hu, Chem. Anal. (Warsaw) 53, 673 (2008).

26. S. Xu, L. Chen, J. Li, Y. Guan and H Lu, J. Hazard. Mater. 237-238, 347 (2012).

27. G. Wu, Z. Wang, J. Wang and C. He, Anal. Chim. Acta 582, 304 (2007).

28. B.S. Batlokwa, L. Chimuka, Z. Tshentu, E. Cukrowska and N. Torto, Water SA 38, 255 (2012).

29. T. Madrakian, B. Zadpour, M. Ahmadi and A. Afkami, J. Iran. Chem. Soc. 12, 1235 (2015).

30. Z. Zhang, J. Li, X. Song, J. Ma and L. Chen, RSC Adv. 4, 46444 (2014).

31. M.R. Ganjali, T. Alizadeh, F. Azimi, B. Larjani, F. Faridbod and P. Norouzi, Int. J. Electrochem. Sci. 6, 5200 (2011).

32. T. Alizadeh, M.R. Ganjali and M. Zare, Anal. Chim. Acta 689, 52 (2011).

33. X.C. Fu, X. Chen, Z. Guo, C.G. Xie, L.T. Kong, J.H. Liu and X.J. Huang, Anal. Chim. Acta 685, 21 (2011).

34. X.C. Fu, J. Wu, L. Nie, C.G. Xie, J.H. Liu and X.J. Huang, Anal. Chim. Acta 720, 29 (2012).

35. M. Karimi, F. Aboufazeli, H.R.L.Z. Zhad, O. Sadeghi and E. Najafi, Orient. J. Chem. 28, 1557 (2012).

36. H.R. Rajabi, M. Roushani and M. Shamsipur, J. Electroanal. Chem. 693, 16 (2013).

37. A. Shirzadmehr, A. Afkhami and T. Madrakian, J. Mol. Liq. 204, 227 (2015).

38. M.R. Ganjali, F. Faridbod, N. Davarkhah, S.J. Shahtaheri and P. Norouzi, Int. J. Environ. Res. 9, 333 (2015).
39. O. Güney and F.Ç. Cebeci, J. Appl. Polym. Sci. 117, 2373 (2010).

40. F. Karagöz and O. Güney, J. Sol-Gel. Sci. Technol. 76, 349 (2015).

41. S. Büyüktiryaki, R. Say, A. Denizli and A. Ersöz, Talanta 71, 699 (2007).

42. Y. Liu, Y. Zai, X. Chang, Y. Guo, S Meng and F. Feng, Anal. Chim. Acta 575, 159 (2006).

43. A.H. Kamel, Life Sci. J. 10, 1657 (2013)

44. A.S. Curry, Br. Med. J. 1, 354 (1964).

45. F. Pehr, Clin. Chem. 21, 1609 (1975).

46. E.Z. Helman, Clin. Chem. 16, 797 (1970).

47. R. Rodríguez-Fernández, Elena PeñaVázquez, and Pilar Bermejo-Barrera, Talanta 144, 636 (2015).

48. M.P. Rodríguez-Reino, R. RodríguezFernández, E. Peña-Vázquez, R. Domínguez-González, P. BermejoBarrera and A. Moreda-Piñeiro, J. Chromatogr. A 1391, 9 (2015).

39. Directive 2008/105/EC of the European Parliament and of the Council of 16 Decembeer 2008 on environmental quality standards in the field of water policy, Off. J. Eur. Union 348, 84-97 (2008). 